\title{
Diagnosis and treatment of invasive pulmonary aspergillosis in neutropenic patients
}

\author{
F. Reichenberger*, J.M. Habicht" ${ }^{\#}$ A. Gratwohl ${ }^{\mp}$, M. Tamm ${ }^{+}$
}

Diagnosis and treatment of invasive pulmonary aspergillosis in neutropenic patients. F. Reichenberger, J.M. Habicht, A. Gratwohl, M. Tamm. (C) ERS Journals Ltd 2002. ABSTRACT: Invasive pulmonary aspergillosis is a major cause of morbidity and mortality in neutropenic patients.

Microbiological and serological tests are of limited value. The diagnosis should be considered in neutropenic patients with fever not responding to antibiotics, and typical findings on thoracic computed tomography scan. Whenever possible, diagnosis should be confirmed by tissue examination. Newer techniques, such as polymerase chain reaction may change the current diagnostic approach.

Therapeutic strategies consist of prophylaxis in risk groups and the early application of antifungal agents in suspected or probable disease. Amphotericin B as desoxycholate or lipid formulation is the current standard medication in invasive infection, although it has major side effects. Its role is challenged by the new azole derivates, such as itraconazole and voriconazole, and the new echinocandins. Additional therapies with cytokines, such as granulocyte macrophage colony stimulating factor and interferon- $\gamma$, and with granulocyte transfusions are under evaluation. In selected cases lung resection is of proven diagnostic and therapeutic value.

This paper analyses the current understanding of the pathogenesis and epidemiology of invasive aspergillosis and reviews the actual diagnostic and therapeutic strategies for invasive pulmonary aspergillosis in neutropenic patients.

Eur Respir J 2002; 19: 743-755.

\begin{abstract}
*Division of Pneumology, Dept of Internal Medicine, University Hospital Leipzig, Germany, " Dept of Cardiothoracic Surgery, and Division of Haematology and ${ }^{+}$Division of Pneumology, Dept of Internal Medicine, University Hospital Basel, Switzerland.
\end{abstract}

Correspondence: F. Reichenberger, Division of Pneumology, Dept of Internal Medicine, University Hospital Leipzig, Johannisallee 32, 04103 Leipzig, Germany.

Fax: 493419712629

E-mail: reichenf@hotmail.com

Keywords: Antifungal therapy, diagnosis, invasive pulmonary aspergillosis, neutropenia, surgery, treatment

Received: July 272001

Accepted after revision September 17 2001
Neutropenic patients are at high risk of infectious complications. Infection with Aspergillus spp. is one of the most serious, because it is difficult to diagnose and it is associated with a high mortality despite adequate therapy $[1,2]$.

Aspergillus is an ubiquitous mould commonly found in humid areas or damp soil. Among 350 species, only seven are facultatively pathogenic. A. fumigatus is the most frequent species found in $90 \%$ of infections. Other pathogenic species include A. flavus, A. niger, A. oryazeae, A. vesicolor, A. terreus, and A. nidulans. The infectious agent is the conidium of $1-3 \mu \mathrm{m}$ in diameter, which can be carried by air. After germination, aspergillus grows with $45^{\circ}$ dichotomous branching of hyphae of $2-5 \mu \mathrm{m}$ diameter, which are able to invade tissue [3].

Antifungal defence in humans is based on normal mucosal barriers, macrophage and neutrophil function. The latter can kill conidiae and inhibit the germination of hyphae. Tumour necrosis factor (TNF)- $\alpha$ and macrophage inflammatory protein (MIP)- $1 \alpha$ are macrophage derived cytokines and crucial in the defence against fungal infections [4]. MIP- $1 \alpha$ is a C-C chemokine with chemotactic and leukocyte activating properties. Both TNF- $\alpha$ and MIP- $1 \alpha$ are released by alveolar macrophages when exposed to aspergillus conidiae. In neutropenia, TNF- $\alpha$ and
MIP- $1 \alpha$ are reduced. Antibody mediated blocking of either TNF- $\alpha$ or MIP- $1 \alpha$ leads to pulmonary invasion of fungal hyphae in non-neutropenic mice. Intratracheal instillation of biologically active TNF- $\alpha$ prior to aspergillus inoculation was associated with a better survival in neutropenic mice [5]. In contrast, aspergillus spores release factors, that can suppress the synthesis of pro-inflammatory cytokines such as interleukin (IL)-1, and TNF- $\alpha$ in macrophages at the transcriptional levels by inhibition of the transcription factor nuclear factor- $\mathrm{KB}$ and activation protein-1 [6].

T-cell function is also important in the development of invasive aspergillosis. Aspergillus antigens are able to induce T-helper (Th)1 and Th2 type reactivity. Th1-reactivity is displayed by an increase of interferon (IFN)- $\gamma$ and IL-12 and has protective effects on the infection. However, Th2 reactivity is characterized by production of IL-4 and IL-10 and leads to disease progression in a murine model of invasive pulmonary aspergillosis (IPA) [7]. The therapeutic consequences of these findings are discussed later.

\section{Epidemiology and risk factors}

Invasive aspergillosis (IA) is a major problem in immunocompromized patients, as in human 
immunodeficiency virus (HIV) infection, after solid organ transplantation, under immunosuppressive or steroid therapy, and in chronic granulomatous disease [8-10]. The highest risk is in neutropenia, where the lungs are affected in $90 \%$ of cases [11].

Invasive fungal infections are most commonly caused by Candida spp. However, while the number of invasive Candida infections declined, there was a ten-fold increase in invasive fungal infections between 1978-1992, mostly caused by Aspergillus spp. [12]. Other pathogenic moulds are Fusaria, Mucor, Alternaria, and Scedosporium. The differentiation is important because of the different susceptibility to antifungal therapy $[13,14]$. The present review focuses on IPA in neutropenia.

Prolonged neutropenia with a granulocyte count $<500 \cdot \mu \mathrm{L}^{-1}$ for $>20$ days is the strongest risk factor for IA [3]. The risk of developing IA increases with the length of neutropenia and reaches a plateau of $70 \%$ after 34 days of granulocytopenia [1].

Patients undergoing myeloablative chemotherapy or stem cell transplantation (SCT) for haematological malignancies are especially at risk of IPA. The frequency of IA in allogeneic SCT recipients is between $5-15 \%[13,15,16]$. Most cases are found in acute myeloid leukaemia (AML). Surprisingly, the outcome in AML patients seems to be better than that of acute lymphoblastic leukaemia or lymphoma patients, probably due to the greater use of corticosteroids in the latter groups [17]. Steroids inhibit macrophage function and predispose to IA [18]. A dose $>0.5 \mathrm{mg}$ prednisone equivalent $\cdot \mathrm{kg}$ body weight ${ }^{-1}$ for $>30$ days is regarded as a substantial risk for IA [16]. IPA develops in $\sim 20 \%$ of allogeneic haematopoietic SCT recipients [19].

After SCT, IA occurs in 2 phases, an early phase $\sim 16$ days after SCT, and a late phase $\sim 96$ days after SCT. Several risk factors of developing IA for both phases have been described (Relative Risk): In the early phase: nonfirst remission of haematological malignancy (8.9), underlying disease (aplastic anaemia, myelodysplasia, nonhaematological malignancy) (5.8), lack of a laminar air-flow room (5.6), SCT in summer (4.4), SCT in autumn (2.2), allogeneic SCT with human leukocyte antigen mismatches (2.1). In the late phase: delayed transplant engraftment with prolonged neutropenia (6.0), age $>40$ yrs (5.0), underlying disease (aplastic anaemia, myelodysplasia, nonhaematological malignancy) (3.7), first remission of the haematological disease (3.6), chronic graft versus host disease (gvhd) requiring treatment with corticosteroids (3.1), nonfirst remission of the haematological disease (3.0), age 20-40 yrs (3.0), acute gvhd >grade 2 (2.6). Further risk factors are a positive cytomegalovirus serostatus at SCT and construction works [13, $14,16,20]$.

The occurrence of aspergillus infection has been clearly related to building hygiene and construction work [21-23]. Building activities have been shown to increase the concentration of aspergillus conidiae in the air with subsequent development of IA [22, 24, 25]. Although this conjunction is still under discussion $[21,26,27]$. The use of high efficiency particulate air (HEPA) filtration units with laminar air flow could markedly reduce the amount of contamination with aspergillus conidiae and the subsequent development of IA $[24,28]$.

\section{Diagnosis of invasive pulmonary aspergillosis}

\section{Clinical signs}

Clinical signs are nonspecific, but characteristic. The occurrence of fever despite appropriate antibiotic therapy for $>96 \mathrm{~h}$ in neutropenic patients is suspicious for IA [29]. Chest pain during breathing and cough are present in $\sim 20 \%$ of IPA cases [30].

Haemoptysis is not an initial symptom of IPA. It occurs when granulocytopenia resolves [31]. The leukocyte reconstitution leads to an overwhelming inflammatory response in the infected lung with local necrosis of the pulmonary parenchyma [32]. Life threatening pulmonary bleeding may occur, and therefore haemoptysis is regarded as a poor prognostic sign in IPA [33].

\section{Radiology}

Radiological imaging is the cornerstone of the diagnosis of IPA, when pulmonary changes develop in neutropenic patients with antibiotic resistant fever. Infiltrates and macronodules are nonspecific changes representing very early infectious consolidation. The appearance of a haemorrhagic pulmonary nodule, termed "halo sign" is typical for IPA. It consists of a nodule-like centre of $\geqslant 50 \%$ (dense fungus ball), surrounded by $\geqslant 180^{\circ}$ ground glass attenuation (coagulation necrosis and haemorrhagic infarction) [34]. The halo is present over a short period of 5-14 days after onset of IPA and has also been found in patients with other pulmonary disorders, such as alveolar haemorrhage, bronchiolitis obliterans organizing pneumonia, viral infections, Kaposi's sarcoma, Wegener's granulomatosis, and angiosarcoma $[35,36,37]$. Based on the few available data its specificity can be calculated at $80 \%$ [38]. The air crescent sign, indicating the development of necrosis, has a sensitivity of 48-68\% and develops mainly from larger consolidations or masses at the time of bone marrow recovery [39]. A cavitary lesion is the late stage of IPA [40].

Plain chest radiography is too insensitive for the diagnosis of IPA. In the early stages nonspecific infiltrates or nodular lesions may be present and the halo sign is not detectable. In the later course of the disease the air crescent sign and cavitation may become visible on plain films [41, 42].

Thoracic computed tomography (CT) scan is the most sensitive radiological method able to detect early changes of IPA (fig. 1a). CT should be performed early in neutropenic patients with antibiotic resistant fever and further clinical signs for IPA [43]. Some investigators perform weekly CT for early detection of IPA [33]. Notably, the volume of the IPA lesion can increase three- to four-fold within the first 7 days despite adequate antifungal treatment [35]. Ultrafast $\mathrm{CT}$ with reduced scanning time has been tested for 

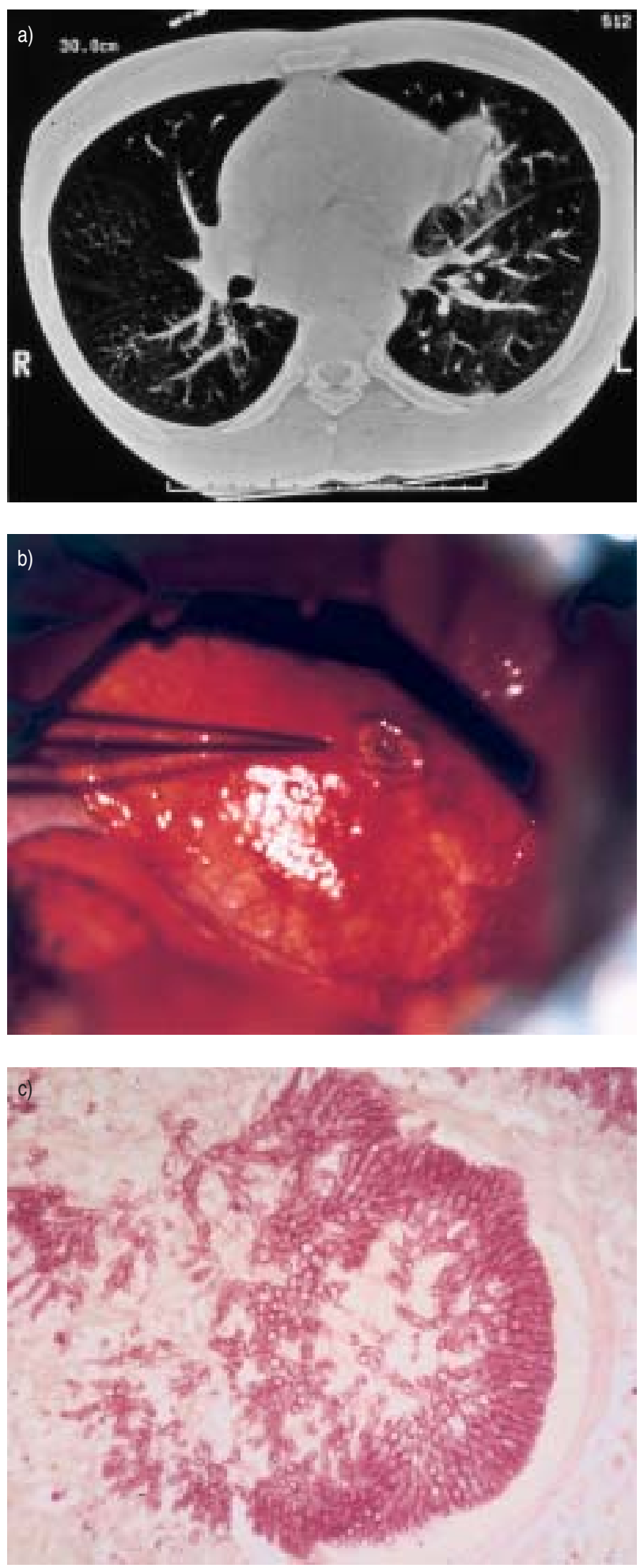

Fig. 1. - a) Thoracic computed tomography scan of a patient with antibiotic resistant neutropenic fever showing a nodular infiltrate in the lingula. When initial antimycotic therapy failed, the patient was scheduled for lung resection. b) The intraoperative appearence during lung resection in the same patient: the invasive fungal infection infiltrates the pericardium. c) Histology of the resected lingula confirmed invasive aspergillosis with fungal hyphae infiltrating the surrounding tissue.

monitoring of IPA in animal studies [44]. Combining the halo sign and the air crescent sign the sensitivity is $>80 \%$ for the diagnosis of invasive mould infection
$[35,36,39-41,43,45,46]$. However, only a few studies have analysed the specificity of these findings reaching $60-98 \%[36,45]$. Based on their own experience, the present authors believe that the new appearance of pulmonary consolidation or infiltrate on a thoracic CT scan in a neutropenic patient with antibiotic resistant fever is already suspicious of IPA [30, 47]. Thoracic CT scanning is the most important diagnostic tool in IPA and has a prognostic impact on the outcome by detection of early changes (table 1).

Magnetic resonance imaging (MRI) has not been extensively studied in IPA so far. The typical pattern of an isointense nodular lesion on a T1-weighted image and a hyperintense centre on T2-weighted image (target sign) with Gadolinium-Diethylenetriamine pentaacetic acid (Gd-DTPA) enhanced rim margin (perilesional haemorrhagic infarction) is present in the later course of the infection. Actually, early diagnosis of IPA can not be achieved by MRI [41].

${ }^{18}$ F-fluoro-2-deoxyglucose positron emission tomography (FDG-PET) is a sensitive method to image inflammatory processes such as hypermetabolic foci. FDG-PET has been sporadically used for monitoring of IA [8]. The usefulness of FDG-PET for the management of IPA requires further evaluation.

\section{Laboratory studies}

Serological testing for IPA is based on detection of antigens. Antibody testing is not useful in neutropenic patients because of the impaired antigen presentation and lymphocyte function [15].

Antigen testing is based on the Galactomannan (GM) antigen, a polysaccharide of the fungal wall, utilized in several test systems. Latex agglutination with monoclonal antibodies $(\mathrm{mAb})$, which recognizes the (1->5)- $\beta$-D-galactofuranoside side chain of the $\mathrm{GM}$, is the commonly used test (Pastorex $\AA$ ) with a sensitivity of $13-95 \%$ and specificity of $86-100 \%$ $[43,45,48-50]$. A cross reactivity of GM-mAb is known against Penicillium spp., and cytotoxic drugs [50].

Enzyme-linked immunosorbent assay (ELISA) of GM antigen using the same antibody for capturing and detection has a 10-15-fold higher sensitivity than latex agglutination [48, 49]. In some studies serum was serially tested for circulating antigen 1-3 times weekly [45, 48-52). An initial study of 19 patients with IPA showed a sensitivity of $95 \%$ and a specificity of $99-100 \%$ for ELISA using either monoclonal or polyclonal antibodies [50]. Studies using the commercially available GM-ELISA with $\mathrm{mAb}$ (Platelia $(\mathrm{R})$ reached a sensitivity between $60-95 \%$ and specificity of $81-100 \%$ in localized and disseminated IPA [48, 49, $51,53]$. A prospective study of serial testing of GMELISA in 362 cases of disseminated IA, among them 72 autopsy controlled cases, confirmed a sensitivity of $90-93 \%$, a specificity of $95-98 \%$, a positive predictive value (ppv) of $87-93 \%$, a negative predictive value (npv) of $95-98 \%$, and a false positive rate of $8-14 \%$ $[52,54]$. In addition, an inhibition ELISA against (1-3)- $\beta$-D-glucan (BDG), a carbohydrate antigen of the aspergillus conidiae of all subspecies, has been 
Table 1. - Value of different diagnostic methods in invasive pulmonary aspergillosis

\begin{tabular}{|c|c|c|c|}
\hline Diagnostic methods & Sensitivity & Specificity & Comments \\
\hline \multicolumn{4}{|l|}{ Thoracic CT scan } \\
\hline Halo/air crescent & $>80$ & $60-98$ & $\begin{array}{l}\text { Specificity only assessed in a few studies, } \\
\text { findings depend on the disease stage }\end{array}$ \\
\hline \multicolumn{4}{|r|}{ 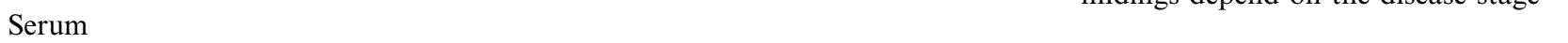 } \\
\hline \multicolumn{4}{|l|}{ Galactomannan Antigen } \\
\hline Latex agglutination (Pastorex $(\mathbb{R})$ & $13-95$ & $86-100$ & Cross reactivity against penicillium \\
\hline 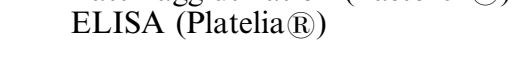 & $90-93$ & $95-98$ & $\begin{array}{l}\text { ppv } 87-93 \text {, npv } 95-98 \\
\text { False positive rate } 8-14\end{array}$ \\
\hline BDG-ELISA & $16-90$ & $76-100$ & $\begin{array}{l}\text { To measure } 1-3 \text { times weekly } \\
\text { ppv } 59, \text { npv } 97\end{array}$ \\
\hline PCR & 100 & $65-92$ & $\begin{array}{l}\text { ppv } 15-44, \text { npv } 100 \\
\text { Useful to exclude aspergillus }\end{array}$ \\
\hline \multicolumn{4}{|l|}{ Bronchoscopy with BAL } \\
\hline Culture & 43 & 100 & Use of Sabouraud medium preferred \\
\hline Galactomannan antigen & $0-80$ & $65-95$ & Highly variable results \\
\hline PCR & $67-100$ & $55-95$ & $\begin{array}{l}\text { ppv } 20-46, \text { npv } 93-100 \\
\text { Useful to exclude aspergillus }\end{array}$ \\
\hline
\end{tabular}

Data are presented as \% unless otherwise stated. CT: computed tomography; ELISA: enzyme-linked immunosorbent assay; BDG: (1-3)- $\beta$-D-glucan; PCR: polymerase chain reaction; BAL: bronchoalveolar lavage; ppv: positive predictive value; npv: negative predictive value.

developed with a sensitivity of $16-90 \%$, a specificity of $76-100 \%$, ppv of $59 \%$ and npv of $97 \%$ for IA $[45,55]$. Recently, the $18 \mathrm{kDa}$ protein mitogillin has been isolated from A. fumigatus, and a role for this antigen in the serodiagnosis of IPA has been suggested [56]. Sensitivity of antigen testing is dependent on the spread of the disease. In localized disease, as in IPA, sensitivity of circulating antigen is significantly lower than in disseminated IA $[45,57]$.

The sensitivity of antigen testing depends on the severity of disease. In localized disease sensitivity is lower than in disseminated disease. Antigen testing should be performed at least once per week in neutropenia for complementary diagnostic screening. Its use for evaluation of a pre-emptive antifungal therapy should be considered.

Polymerase chain reaction (PCR) in serum for Aspergillus spp. was introduced in 1996, using a nested PCR method [58]. Target genes are the 135-bp fragment in the mitochondrial DNA [59], the multicopy 18S ribosomal ribonucleic acid (rRNA) in Aspergillus spp. [58-63], and the 401-bp fragment in the ribosomal deoxyribonucleic acid (rDNA) complex of A. fumigatus [64]. Several methods including real time PCR, nested PCR, and two step PCR have been described [58-66]. A differentiation of the subspecies of Aspergillus spp. at genomic level is feasible using the internal transcribed spacer regions between $18 \mathrm{~S}$ and the 28S rRNA [67]. PCR testing is of promise but under evaluation. So far the results are highly variable. The largest published study shows a sensitivity of $100 \%$, a specificity of $65-92 \%$, a ppv between $15-44 \%$, and a npv of $100 \%$ [60]. These results were achieved by serial testing [59-62]. A study comparing the diagnostic sensitivity of PCR versus GM-ELISA revealed a higher sensitivity of ELISA of $40 \%$ versus PCR of $10 \%$ [59]. Further data from prospective histology controlled studies are needed to evaluate this method (table 1).

\section{Bronchoscopy}

Bronchoscopy with bronchoalveolar lavage (BAL) is an established tool for the diagnosis of infectious complications in neutropenic patients [68] as well as after bone marrow transplantation [69]. Its value in the diagnosis of IPA, however, requires critical analysis [70]. Aspergillus can be found in the BAL or in bronchial washings by culture, by microscopy with detection of mould hyphae, by detection of the aspergillus antigen, or by PCR.

For identification of aspergillus, BAL is cultured in Sabouraud medium, a fungal culture medium that is superior to the routine bacterial culture medium [71]. Microscopy of BAL for mould hyphae is usually performed after haematoxylin-eosin or Grocott's staining.

Recently the present authors reviewed the value of aspergillus culture and microscopy in BAL and found a sensitivity of $43 \%$ and a specificity of $100 \%$ in histologically proven cases of IPA. BAL was more often positive in multilobular IPA than in localized disease, irrespective of the duration of pretreatment with Amphotericin B (AmB) [72]. The sensitivity for detecting IPA increases with multiple cultures [71]. It has been reported that a positive fungal culture from secretion indicates a poor prognosis [33].

Detection of aspergillus antigen in BAL has been studied by only few groups. After early promising results for radio-immunoassay of GM-antigen [73], further studies reported a sensitivity between $0-80 \%$ and a specificity of $65-70 \%$ using GM antigen latex agglutination in histologically proven IPA [43, 74], and $37-67 \%$ sensitivity and $95 \%$ specificity for GMELISA in probable IPA [75].

PCR in BAL was introduced in 1993 as an indicator of aspergillus infection or colonization. Since then results with several PCR systems and primers have been reported. PCR in BAL has an estimated 
sensitivity of $67-100 \%$ and a specificity between $55-95 \%$, a ppv ranging between $20-46 \%$ and a npv between $93-100 \%$. This technique is useful to exclude aspergillus infection [63, 66, 75-77] (table 1).

\section{Tissue examination}

Tissue examination is performed for definite diagnosis or exclusion of IPA. Furthermore, it enables the distinction between colonization and invasive infection to be made, and allows other invasive infections requiring different therapy to be diagnosed.

Transbronchial biopsy (TBB) is an established method in the diagnosis of invasive pulmonary infections in immunocompromized patients. But TBB requires a thrombocyte count of $\geqslant 50,000 \cdot \mu \mathrm{L}^{-1}$ to avoid a greater risk of bleeding, and this technique can not be routinely performed in pancytopenic patients [78].

CT guided percutaneous lung biopsy has been performed with a diagnostic yield of $80-100 \%$. This procedure requires a thrombocyte count $>60,000 \cdot \mu \mathrm{l}^{-1}$, but nevertheless bleeding occurs in $46 \%$ of cases. Furthermore, it carries a high risk of pneumothorax [37]. This procedure can not be recommended in neutropenic patients.

Open lung biopsy has been advocated for confirmation of the underlying disease. However these patients are high-risk candidates for perioperative complications, and surgery for diagnostic reasons alone is not advisable [79]. The value of lung resection in the therapy of IPA is discussed below.

\section{Classification of the invasive pulmonary aspergillosis diagnosis}

Because of the difficulties in diagnosis of IPA, the Mycosis Study Group suggested the following definitions [17, 80, 81]: 1) Definite IPA: septate branching hyphae in tissue histopathology, or positive culture from tissue obtained by an invasive procedure; 2) Probable IPA: appearance of new nodules or cavities on a chest radiograph in neutropenic patients, receipt of a cytotoxic agent for a malignant or immunological disease, steroid use of $>10 \mathrm{mg}$ prednisone equivalent or congenital or acquired immunodeficiency. Two sputum cultures or one BAL, bronchial washing/ brushing culture positive for Aspergillus spp. or cytological examination on BAL showing characteristic hyphae, or two positive PCR for aspergillus in the BAL; 3) Possible IPA: radiological findings typical of invasive aspergillosis such as a halo sign or cavitation in neutropenic or previously neutropenic patients and positive sputum or endotracheal culture for Aspergillus spp.

\section{Treatment of invasive pulmonary aspergillosis}

\section{Prophylaxis}

Patients at high risk of developing IPA should be identified prior to myeloablative therapy. Isolation of these patients and use of a HEPA filtration during neutropenia should be mandatory [21, 24, 28, 82]. Medical prophylaxis of IPA is discussed later.

\section{Amphotericin B}

$\mathrm{AmB}$ is an ergosterol-binding polyene leading to disintegration of the fungal membrane. Since its development in 1952, different formulations of AmB have been developed. The conventional formulation is AmB-desoxycholate $(\mathrm{cAmB})$. This is the standard therapy for IPA at a dosage of $1-1.5 \mathrm{mg} \cdot \mathrm{kg}$ bodyweight $^{-1} \cdot$ day $^{-1}$ [83]. The recommended run-in phase with reduced dose can be safely decreased to $24-48 \mathrm{~h}$ [29]. Sometimes fever and shivering occur during cAmB infusion. Typical side-effects are electrolyte imbalance and progressive renal failure despite adequate prophylaxis in $\sim 50 \%$ of patients, requiring dose adjustment. Electrolyte imbalance can be reduced by appropriate substitution and infusion of electrolytes prior to $\mathrm{cAmB}$ application. $\mathrm{cAmB}$ itself should be given solely in $5 \%$ glucose solution. Continuous infusion of cAmB over $24 \mathrm{~h}$ can significantly reduce nephrotoxicity [84]. Approximately $33-54 \%$ of patients with IA respond to $\mathrm{cAmB}$ therapy [80], however mortality exceeds 64-90\% despite adequate treatment $[1,2,85,86]$.

Local administration of $\mathrm{cAmB}$, an effective therapeutic option in aspergilloma, has been performed occasionally in IPA [87]. Percutaneous CT guided application of $\mathrm{AmB}$ has been proven to be effective in a small series of IPA [88]. However, thrombocyte counts must be $>50,000 \cdot \mu \mathrm{L}^{-1}$ to prevent bleeding, and there is a substantial risk of pneumothorax. Endobronchial instillation of $\mathrm{AmB}$ has been reported with variable results [89]. A small series of patients successfully treated with a combination therapy of systemic and local AmB has been reported [90].

In the therapy of antibiotic resistant neutropenic fever of unknown aetiology the systemic application of $\mathrm{cAmB}$ is recommended [91, 92]. Application of AmB has not been shown to be beneficial for prophylaxis of IPA in neutropenia [93]. Low dose intravenous $\mathrm{cAmB}$, inhalation of $\mathrm{cAmB}$ as well as intranasal $\mathrm{cAmB}$ application are well tolerated, but failed to be effective in prevention of IPA [21, 82, 94, 95].

Lipid-bound formulations of AmB exhibit the same microbiological activity and are well tolerated. Because they are less nephrotoxic than $\mathrm{cAmB}$, higher doses of the active antifungal compound can be administered [96]. The overall response rate is around 40-70\% [86]. Lipid bound AmB should be used in patients with IPA, who have severe side-effects or fail to respond to $\mathrm{CAmB}$ therapy [97].

Liposomal AmB (AmBisome $\mathbb{R}$ ) achieves response rates of $30-60 \%$ in IA. It is less nephrotoxic than $\mathrm{cAmB}$. The recommended dose ranges between 1-3 $\mathrm{mg} \cdot \mathrm{kg}^{-1} \cdot \mathrm{day}^{-1}$, but can be increased to $6 \mathrm{mg} \cdot \mathrm{kg}^{-1}$. However, reports of beneficial effects of doses $>3 \mathrm{mg} \cdot \mathrm{kg}^{-1}$ are discrepant [85, 98, 99]. In febrile neutropenia, AmBisome $\mathbb{R}$ in a dose of $3 \mathrm{mg} \cdot \mathrm{kg}^{-1}$ is as effective as $\mathrm{cAmB}$, but is associated with less side-effects, nephrotoxicity, and breakthrough fungal 
infections [83]. The prophylactic administration of AmBisome $\mathbb{B}$ three-times weekly could reduce the rate of fungal colonization but not of invasive fungal infections in neutropenic patients [100].

Colloid dispersion of AmB (Amphocilß) consists of an equimolar mixture of AmB and cholesterylsulfate. The recommended dose is $3-4 \mathrm{mg} \cdot \mathrm{kg}$ bodyweight ${ }^{-1} \cdot$ day $^{-1}$. In patients with IA a response rate of $38-48 \%$ has been reported [101]. Amphocil $\AA$ is also effective in the therapy of neutropenic fever [102]. There is less renal toxicity than with $\mathrm{cAmB}$, although its use is limited by severe side-effects such as fever, chills, and hypoxia despite adequate premedication leading to the early termination of a randomized trial [101-104].

Lipid Complex of AmB (Abelcet $\mathbb{R}$ ) is supposed to have a response rate of $42-67 \%$ but less nephrotoxicity. The recommended dose is $4.8 \mathrm{mg} \cdot \mathrm{kg}^{-1} \cdot \mathrm{day}^{-1}$. The use is limited by side-effects such as infusion-related chills, rigor, and fever [105]. Abelcet $\mathbb{R}$ is more nephrotoxic and less effective in the therapy of neutropenic fever compared to AmBisome $\mathbb{R}$ [106].

Application of $\mathrm{cAmB}$ in fatty-acid emulsion is not recommended because antimycotic beneficial effects are lacking and there have been severe renal and pulmonary side-effects, probably due to fat emboli [107].

Resistance of Aspergillus spp. to AmB treatment arises from altered ergosterol content of the fungus membrane. A. fumigatus and $A$. niger are well susceptible to AmB therapy, but $A$. terreus and $A$. flavus exhibit high minimal inhibition concentrations (MIC) in vitro. All of the lipid associated AmB compounds show higher MIC values than $\mathrm{cAmB}$ for all
Aspergillus spp. However the correlation of clinical failure of AmB therapy and resistance is difficult to prove in these severely immunosuppressed neutropenic patients [108]. In vitro studies have demonstrated, that previous azole therapy may induce AmB resistance by reducing the amount of ergosterol in the fungus membrane [109] (table 2).

\section{Azoles}

Azoles inhibit the P450 dependent lanosterol 14- $\alpha$ demethylase, a late step in ergosterol synthesis. This leads to disintegration of the fungal cell membrane. The early azoles such as clotrimazole, miconazole, and ketoconazole were not effective enough to be relevant in the therapy of IA. The first triazole, fluconazole showed only in vitro activity against IA [110]. The further development of triazoles has led to compounds effective against Aspergillus spp. in vivo.

Itraconazole has been shown to be as effective as $\mathrm{AmB}$ in patients with IA. Oral and intravenous itraconazole is used in the therapy and primary and secondary prophylaxis of IA [111]. The oral formulation has a response rate of between 39-66\%. The recommended dose is $400-600 \mathrm{mg} \cdot$ day $^{-1}$ [80, 86, 112]. Side-effects include a nasty taste in the mouth, nausea, vomiting, and diarrhoea leading to a limited compliance in some patients [113]. Furthermore, the gastrointestinal resorption of itraconazole is highly variable depending on the gastric $\mathrm{pH}$, with a consequent danger of breakthrough mould infection, especially in patients with gvhd [114]. The fluid oral solution is able to maintain stable plasma drug

Table 2. - Medical therapy in invasive pulmonary aspergillosis

\begin{tabular}{|c|c|c|c|}
\hline Medical therapy & Dosage & Response \% & Comments \\
\hline \multicolumn{4}{|l|}{ Amphotericine B } \\
\hline Desoxycholate & $1-1.5 \mathrm{mg} \cdot \mathrm{kg}^{-1}$ & $33-54$ & $\begin{array}{l}\text { Mortality of } 64-90 \% \\
\text { Fewer side effects in continuous } 24 \mathrm{~h} \text { infusion } \\
\text { Local instillation possible } \\
\text { Not effective in prophylaxis }\end{array}$ \\
\hline Colloid dispersion & $3-4 \mathrm{mg} \cdot \mathrm{kg}^{-1}$ & $38-48$ & $\begin{array}{l}\text { Less nephrotoxicity, but severe } \\
\text { side-effects as fever, chills, hypoxia }\end{array}$ \\
\hline Lipid complex & $4.8 \mathrm{mg} \cdot \mathrm{kg}^{-1}$ & $42-67$ & Less nephrotoxicity, but chills, rigor, fever \\
\hline Liposomal & $1-3(-6) \mathrm{mg} \cdot \mathrm{kg}^{-1}$ & $30-60$ & $\begin{array}{l}\text { Less nephrotoxicity } \\
\text { Less breakthrough infections } \\
\text { Reduced aspergillus colonization }\end{array}$ \\
\hline \multicolumn{4}{|r|}{ सені } \\
\hline Itraconazole & Oral $400-600 \mathrm{mg}$ & $39-66$ & $\begin{array}{l}\text { Side effects: nausea and vomiting } \\
\text { Better resorption as oral solution }\end{array}$ \\
\hline Voriconazole & i.v. $200 \mathrm{mg}$ & $\begin{array}{c}48 \\
50-75\end{array}$ & $\begin{array}{l}\text { Long term therapy induces resistance } \\
\text { Visual, hepatic, and dermal side effects } \\
\text { FDA approval pending }\end{array}$ \\
\hline Posaconazole & & 53 & FDA approval pending \\
\hline Racuvonazole & & & Only animal studies \\
\hline \multicolumn{4}{|l|}{ Echinocandins } \\
\hline Caspofungin (MK-0991) & & $41-45$ & Preliminary data from clinical trials \\
\hline FK 463 & & & In clinical trials \\
\hline LY-303366 & & & In clinical trials \\
\hline Papulacandins & & & In development \\
\hline Acidic terpenoids & & & In development \\
\hline
\end{tabular}

FDA: Food and Drug Administration. 
concentrations [115]. Intravenous application of itraconazole at a dose of $200 \mathrm{mg} \cdot \mathrm{day}^{-1}$ was effective in $48 \%$ of the patients and it is shortly to be licensed in Europe. Strains of $A$. fumigatus resistant to itraconazole have already been described [116].

In vitro testing showed resistance to itraconazole in $1.5-4.2 \%$ of isolates with a $\mathrm{MIC}>8$. Long-term therapy with itraconazole can induce resistance to that compound [117]. Cross reactivity to other triazoles has been reported, mainly to posaconazole, but not to voriconazole so far.

Voriconazole is a newly developed triazole with a high activity against Aspergillus spp., but also against Scedosporium and Fusarium. It has been tested since 1995 in IA. This compound is more effective than itraconazole or AmB in animal models of IPA [118, 119]. Oral and intravenous application exhibits a $50-75 \%$ response rate in patients with IA [96, 109]. Voriconazole is well tolerated, typical side-effects consist of visual disturbances, hepatotoxicity, and dermal rash.

Voriconazole is as effective as AmBisome $\mathbb{R}$ in neutropenic fever, but has less nephrotoxicity, hepatotoxicity, breakthrough fungal infections, and acute infusion-related toxic effects. However its use is associated with a higher rate of infusion related visual side-effects [120]. In vitro testing of voriconazole showed a MIC $>8$ in $3.5 \%$ of isolates. [108]. The approval by the Food and Drug Administration (FDA) is still pending [109].

Among the new and more powerful triazoles, posaconazole and racuvonazole are two compounds highly active against aspergillus compared to other antimycotics [121, 122]. In a preliminary study in therapy-refractory IA in humans, posaconazole showed a response rate of $53 \%$. Furthermore, this compound possesses lower MIC in vitro against all Aspergillus spp. compared to the other triazoles [108]. Ravuconazole has only been tested in animal studies so far [109] (table 2).

\section{Echinocandins}

Echinocandins are natural inhibitors of the BDG synthetase, an enzyme that forms glucan polymers in the fungus wall [109, 123]. Echinocandins are antifungal lipopeptides firstly isolated from Aspergillus spp. in 1974. The distinct term pneumocandin is derived from the originally observed activity against pneumocystis and candida [124]. In the last $20 \mathrm{yrs}$ biologically stable semisynthetic derivatives have been developed, which have proved to be effective in prophylaxis and therapy of IPA in animal models [125].

Caspofungin (MK-0991), a noncompetitive inhibitor of the BDG-synthetase derived from an antifungal substance of Zalerion arboricola, has been recently approved by the FDA. In a preliminary study of 54 patients with IA, a $41 \%$ response rate with caspofungin has been achieved, among these were 40 IPA patients with a $45 \%$ response rate. In the subset of 44 patients with resistance or intolerance to $\mathrm{AmB}$ and azole therapy, a favourable response to caspofungin has been observed in 34\% [81].

Other echinocandins such as FK 463 and LY303366 are being tested in clinical trials. Additional BDG-synthetase-inhibitors, for instance the glycolipid papulacandins and the acidic terpenoids are in development [123].

\section{Other antifungal compounds}

Several new classes of antifungals with activity against aspergillus are in development or have been tested in animal studies. Liposomal nystatin showed good in vitro activity against Aspergillus spp. [126]. Pradimicins destroy the fungal wall by binding to mannosides. Nikkomycins inhibit chitin synthesis and are supposed to act synergistically with triazoles [109]. Further antifungal strategies are reviewed elsewhere [127] (table 2).

\section{Combination therapy}

Several compounds have been evaluated for combination therapy in IA and IPA including AmB, itraconazole, flucytosin, and echinocandins.

Application of AmB and itraconazole has been shown to be more effective than either AmB or itraconazole alone [17, 128]. However, case fatality rates are similar with a combination of $\mathrm{AmB}$ and itraconazole compared to AmB only [86]. Furthermore, an antagonistic mechanism of these compounds were described in vitro [129].

The combination of $\mathrm{AmB}$ and 5-Flucytosin is effective in several fungal infections, but the combination was not beneficial compared to AmB monotherapy in neutropenic patients with systemic mycoses $[1,130]$. Flucytosin has myelosuppressive side-effects and may multiply the nephrotoxic side-effects of AmB [96].

There are few data on combined application of AmB and echinocandins. In an animal study of IPA, $\mathrm{AmB}$ and the echinocandin FK 463 showed synergistic action [109]. Results from clinical trials of combination therapy of AmB or triazoles with echinocandins have not yet been published.

Combination antifungal therapy is not recommended routinely, however it might be effective in individual cases.

\section{Cytokines}

Use of cytokines has been suggested to increase antifungal immune response. Colony stimulating factors have been used to shorten the neutropenic phase. In particular granulocyte macrophage stimulating colony (GM-CSF), with its ability to increase the lifespan of neutrophils and to promote monocyte differentiation has been used successfully. GM-CSF has been shown to be effective in invasive fungal infections other than aspergillosis [131]. However, during bone marrow recovery with an increase in 
granulocyte count there is a substantial risk of potentially fatal pulmonary haemorrhage, especially when granulocyte counts normalize within one week after aplasia [31, 32, 132, 133]. The use of GM-CSF in invasive aspergillosis is not recommended routinely.

Several other cytokines have been discussed in antifungal strategies $[9,10]: 1)$ IFN- $\gamma$ has been shown to increase the antifungal activity of macrophages and neutrophils. It is able to prevent the injurious effects of steroids on neutrophil activity against aspergillus; 2) IL-12, normally derived from macrophages, is able to stimulate Th1 lymphocytes, which produce IFN. Furthermore IL-12 stimulates natural killer cells which also have antifungal activity and can produce IFN; 3) Neutralization of IL-4 and IL-10 attenuates the Th2 response and is associated with increased antifungal activity [9].

None of these cytokines are established in the therapy of IPA, and results from randomized, controlled trials are not available. The use of cytokines cannot currently be recommended.

\section{Granulocyte transfusion}

Other options include granulocyte transfusion, which has been performed with variable success [8, $134,135]$. It seems to be beneficial in selected cases, as in patients with severe aplastic anaemia and prolonged periods of neutropenia. Furthermore, patients with proven IPA, who are planning to undergo allogeneic SCT should benefit from granulocyte transfusion from the stem cell donor. Results from randomized trials are not yet available.

\section{Surgery}

Lung resection has been performed as an emergency procedure in IPA when haemoptysis has occurred [1]. The radical removal of the IPA lesion seemed to influence the outcome of IPA and enabled subsequent immunoablative therapy $[30,47]$. Therefore, surgery has been advocated as a therapeutic option in localized IPA.

Lung resection has both diagnostic and therapeutic impact. It is able to obtain a specimen for precise histological diagnosis of the pulmonary changes. Furthermore the infectious focus is removed, and complications arising from IPA such as disseminated infection or haemoptysis are prevented.

Early studies on highly-selected patients have proved the feasibility of this procedure [136]. However perioperative complications including infections, fungal relapse, and bleeding need to be considered [33, 137]. Nevertheless, surgery has been advocated in the early stages of IPA [43]. The decision to perform lung resection is based on clinical and radiological signs of IPA rather than microbiological findings. Surgery is also feasible in profound neutropenia and thrombocytopenia [30, 31, 138, 139]. Also in multilocular IPA multiple wedge resections can be performed [138]. Besides lobectomy, lung parenchyma saving procedures such as open wedge resection and video-assisted thoracoscopic surgical interventions are feasible [30].
In recent published studies 165 patients were reported, who underwent lung resection for IPA. Twelve patients had nonfatal postoperative complications that needed intervention $(7 \%)$, and 24 died postoperatively (14\%). In 27 patients uncontrolled or recurrent mould infection was reported $(16 \%)$. After lung resection, 35 patients underwent SCT, whereas in three patients fungal relapse occurred $(8 \%)$ $[30,33,43,47,136,137,140]$.

In a retrospective analysis of the outcome of patients with IPA comparing medical and surgical therapy, lung resection was associated with better survival and reduced IPA related mortality [141]. Therefore lung resection should be considered in patients with clinical and radiological signs of localized or multilocular IPA: early in the course of IPA, who failed to respond to antifungal therapy, prior to further immunosuppressive therapy, e.g. ablative chemotherapy or SCT, when haemoptysis occurs.

The preoperative microbiological detection of a mould infection is not essential. Neutropenia is not regarded as contraindication, but disseminated IPA is not regarded as indication for surgery (table 3 , fig. 1a-c).

\section{Prognosis}

The strongest prognostic factor for IPA is successful therapy of the underlying disease. In patients with acute leukaemia and IPA, the complete remission of the haematological disease was the main prognostic factor associated with a significantly better outcome [142]. After surgery for IPA, the survival of patients was limited due to relapse or uncontrolled malignancy, but not by complications of the surgical procedure [30].

\section{Summary}

Invasive pulmonary aspergillosis in neutropenia, carrying an increasing morbidity and still a high mortality, is a diagnostic and therapeutic challenge.

Table 3.-Surgery in invasive pulmonary aspergillosis (IPA): indication and risks

\begin{tabular}{ll}
\hline $\begin{array}{c}\text { Indication for } \\
\text { Surgery }\end{array}$ & $\begin{array}{l}\text { Localized or multilocular IPA } \\
\text { Early stage IPA } \\
\text { Failure of antifungal therapy } \\
\text { Planned immunosuppression, } \\
\text { e.g. HDC or SCT } \\
\text { Haemoptysis }\end{array}$ \\
$\begin{array}{l}\text { Perioperative } \\
\text { mortality }\end{array}$ & $7 \%$ (24 of 165 patients) \\
$\begin{array}{c}\text { Postoperative } \\
\text { complications } \\
\text { (nonfatal) }\end{array}$ & $16 \%$ of 165 patients $)$ \\
$\begin{array}{c}\text { Recurrent mould } \\
\text { infection }\end{array}$ & $8 \%$ of 165 patients $)$ \\
$\begin{array}{c}\text { Fungal relapse } \\
\text { post SCT }\end{array}$ & \\
\hline
\end{tabular}

HDC: high dose chemotherapy; SCT: stem cell transplantation. 
It requires a network approach of diagnostic, prophylaxis and therapeutic strategies. Identification of high-risk patients, appropriate prophylaxis, diagnostic surveillance, and early diagnosis are important for early initiation of adequate therapy. In addition to thoracic computed tomography scanning, newer diagnostic strategies should incorporate polymerase chain reaction techniques in serum and bronchoalveolar lavage. Therapeutic options include new antifungal compounds (triazoles and echinocandins) and cytokine therapy. Parenchyma saving surgical procedures should be considered early in the course of invasive pulmonary aspergillosis in patients with localized disease.

\section{References}

1. Denning DW, Stevens DA. Antifungal and surgical treatment of invasive aspergillosis. Review of 2,121 published cases. Rev Infect Dis 1990; 12: 1147-1201.

2. Jantunen E, Ruutu P, Piilonen A, Volin L, Parkkali T, Ruutu T. Treatment and outcome of invasive aspergillus infections in allogeneic BMT recipients. Bone Marrow Transplant 2000; 26: 759-762.

3. Sharma OP, Chwogule R. Many faces of pulmonary aspergillosis. Eur Respir J 1998; 12: 705-715.

4. Mehrad B, Moore TA, Standiford TJ. Macrophage inflammatory protein-1alpha is a critical mediator of host defense against invasive pulmonary aspergillosis in neutropenic hosts. J Immunol 2000; 165: 962-968.

5. Mehrad RM, Strieter B, Standiford TJ. Role of TNFalpha in pulmonary host defense in murine invasive aspergillosis. J Immunol 1999; 162: 1633-1640.

6. Nicholson WJ, Slight J, Donaldson K. Inhibition of the transcription factors $\mathrm{NK}-\mathrm{kB}$ and $\mathrm{AP}-1$ underlies loss of cytokine gene expression in rat alveolar macrophages treated with a diffusible product from the spores of aspergillus fumigatus. Am J Respir Cell Mol Biol 1996; 15: 88-96.

7. Cenci E, Mencacci A, Bacci A, Bistoni F, Kurup VP, Romani L. T Cell Vaccination in mice with invasive pulmonary aspergillosis. J Immunol 2000; 165: 381388.

8. Ozahin H, von Planta M, Müller I, et al. Successful treatment of invasive aspergillosis in chronic granulomatous disease by bone marrow transplantation, granulocyte colony-stimulating factor-mobilized granulocytes, and liposomal amphotericin-B. Blood 1998; 92: 2719-2724.

9. Stevens DA. Combination immunotherapy and antifungal chemotherapy. Clin Infect Dis 1998; 26: 1266 1269.

10. Rodriquez-Adrian LJ, Grazziutti ML, Rex JH, Anaissie EJ. The potential role of cytokine therapy for fungal infection in patients with cancer: is recovery from neutropenia all that is needed? Clin Infect Dis 1998; 126: 1270-1278.

11. Patterson TF, Kirkpatrick WR, White $\mathrm{M}$, et al. Invasive aspergillosis. Disease spectrum, treatment practices, and outcome. I3 Aspergillus Study Group. Medicine 2000; 79: 250-260.

12. Groll AH, Shah PM, Mentzel C, Schneider M, JustNuebling G, Hueber K. Trends in the postmortem epidemiology of invasive fungal infections at a university hospital. $J$ Infect 1996; 33: 23-32.
13. Jantunen E, Ruutu P, Niskanen L, et al. Incidence and risk factors for invasive fungal infections in allogeneic BMT recipients. Bone Marrow Transplant 1997; 19: 801-808.

14. Morrison VA, Haake RJ, Weisdorf DJ. Non-candida fungal infections after bone marrow transplantation: risk factor and outcome. Am J Med 1994; 96: 497-503.

15. Saugier-Veber P, Devergie A, Sulahian A, et al. Epidemiology and diagnosis of invasive pulmonary aspergillosis in bone marrow transplant patients: results of a 5 year retrospective study. Bone Marrow Transplant 1993; 12: 121-124.

16. Baddley JW, Stroud TP, Salzman D, Pappas PG. Invasive mold infections in allogeneic bone marrow transplant recipients. Clin Infect Dis 2001; 32: 1319_ 1324.

17. Denning DW, Marinus A, Cohen J, et al. An EORTC multicentre prospective survey of invasive aspergillosis in haematological patients: diagnosis and therapeutic outcome. J Infect 1998; 37: 171-180.

18. Berenguer J, Allende MC, Lee JW, et al. Pathogenesis of pulmonary aspergillosis. Am J Respir Crit Care Med 1995; 152: 1079-1086.

19. Nicod LP, Pache J-C, Howarth N. Fungal infections in transplant recipients. Eur Respir J 2001; 17: 133140 .

20. Wald A, Leisenring W, van Burik JA, Bowden RA. Epidemiology of aspergillus infections in a large cohort of patients undergoing bone marrow transplantation. J Infect Dis 1997; 175: 1459-1466.

21. Oren I, Haddad N, Finkelstein R, Rowe JM. Invasive pulmonary aspergillosis in neutropenic patients during hospital construction: before and after chemoprophylaxis and institution of HEPA filters. Am J Hematol 2001; 66: 257-262.

22. Anderson K, Morris G, Kennedy H, et al. Aspergillus in immunocompromised paediatric patients: association with building hygiene, design, and indoor air. Thorax 1996; 51: 256-261.

23. Ruutu P, Valtonen V, Tiitanen L, et al. An outbreak of invasive aspergillosis in a haematologic unit. Scand J Infect Dis 1987; 19: 347-351.

24. Barnes RA, Rogers TR. Control of an outbreak of nosocomial aspergillosis by laminar air-flow isolation. J Hosp Infect 1989; 14: 89-94.

25. Iwen PC, Davis JC, Reed EC, Winfield BA, Hinrichs $\mathrm{SH}$. Airborne fungal spore monitoring in a protective environment during hospital construction, and correlation with an outbreak of invasive aspergillosis. Infect Control Hosp Epidemiol 1994; 15: 303-306.

26. Hospenthal DR, Kwon-Chung KJ, Bennett JE. Concentration of airborne aspergillus compared to the incidence of invasive aspergillosis: lack of correlation. Med Mycol 1998; 36: 165-168.

27. Goodley JM, Clayton YM, Hay RJ. Environmental sampling for aspergilli during building construction on a hospital site. J Hosp Infect 1994; 26: 27-35.

28. Sheretz RJ, Belani A, Kramer BS, et al. Impact of air filtration on nosocomial aspergillus infection. Unique risk of bone marrow transplant recipients. $\mathrm{Am} \mathrm{J} \mathrm{Med}$ 1987; 83: 709-718.

29. Böhme A, Karthaus M. Systemic fungal infections in patients with hematologic malignancies: indications and limitations of the antifungal armamentarium. Chemotherapy 1999; 45: 315-324.

30. Reichenberger F, Habicht J, Kaim A, et al. Lung resection for invasive pulmonary aspergillosis in 
neutropenic patients with hematologic diseases. $\mathrm{Am}$ J Respir Crit Care Med. 1998; 158: 885-890.

31. Pagano L, Ricci P, Nosari A, et al. Fatal haemoptysis in pulmonary filamentous mycosis: an underevaluated cause of death in patients with acute leukaemia in haematological complete remission. A retrospective study and review of the literature. Br J Haematol 1995; 89: 500-505.

32. Albelda SM, Talbot GH, Gerson SL, Miller WT, Cassileth PA. Pulmonary cavitation and massive hemoptysis in invasive pulmonary aspergillosis. Influence of bone marrow recovery in patients with acute leukemia. Am Rev Respir Dis 1985; 131: 115-120.

33. Yeghen T, Kibbler CC, Prentice HG, et al. Management of invasive pulmonary aspergillosis in hematologic patients: A review of 87 consecutive cases at a single institution. Clin Infect Dis 2000; 31: 859-868.

34. Hruban RH, Meziane MA, Zerhouni EA, Wheeler PS, Dumler JS, Hutchins GM. Radiologic-pathologic correlations of the CT halo sign in invasive pulmonary aspergillosis. J Comput Assist Tomogr 1987; 11: 534 536.

35. Caillot D, Couaillier JF, Bernard A, et al. Increasing volume and changing characteristics of invasive pulmonary aspergillosis on sequential thoracic computed tomography scans in patients with neutropenia. J Clin Oncol 2001; 19: 253-259.

36. Won HJ, Lee KS, Cheon JE, et al. Invasive pulmonary aspergillosis: prediction at thin section CT in patients with neutropenia - a prospective study. Radiology 1998; 208: 777-782.

37. Primack SL, Hartmann TE, Lee KS, Müller NL. Pulmonary nodule and the CT halo sign. Radiology 1994; 190: 513-515.

38. Hoffer FA, Gow K, Flynn PM, Davidoff A. Accuracy of percutaneous lung biopsy for invasive pulmonary aspergillosis. Pediatr Radiol 2001; 31: 144-152.

39. Kim MJ, Lee KS, Kim J, Jung KJ, Lee HG, Kim TS. Crescent sign in invasive pulmonary aspergillosis: frequency and related CT and clinical factors. $J$ Comput Assist Tomogr 2001; 25: 305-310.

40. Kuhlmann JE, Fishman EK, Siegelman SS. Invasive pulmonary aspergillosis in acute leukemia: characteristic findings on CT, the CT halo sign, and the role of CT in early diagnosis. Radiology 1985; 157: 611-614.

41. Blum U, Windfuhr M, Buitrago-Teelz C, Sigmund G, Herbst EW, Langer M. Invasive pulmonary aspergillosis. MRI, CT, and plain radiographic findings and their contribution for early diagnosis. Chest 1994; 106 : 1156-1161.

42. Pasmans HLM, Lossveld OJL, Schouten HC, Thunnissen F, van Engelshoven JMA. Invasive aspergillosis in immunocompromised patients: findings on plain film and (HR) CT. Eur J Radiol 1992; 14: 37-40.

43. Caillot D, Casanovas O, Bernard A, et al. Improved management of invasive pulmonary aspergillosis in neutropenic patients using early thoracic computed tomography scan and surgery. J Clin Oncol 1997; 15: 139-147.

44. Walsh TJ, Garrettt K, Feuerstein E, et al. Therapeutic monitoring of experimental invasive pulmonary aspergillosis by ultrafast computerized tomography, a novel noninvasive method for measuring response to antifungal therapy. Antimicrob Agents Chemother 1995; 39: 1065-1069.

45. Kami M, Tanaka Y, Kanda Y, et al. Computed tomographic scan of the chest, latex agglutination test, and plasma (1->3)- $\beta$-glucan assay in early diagnosis of invasive pulmonary aspergillosis: A prospective study of 215 patients. Haematologica 2000; 85: 745-752.

46. Mori M, Galvin JR, Barloon TJ, Gingrich RD, Stanford W. Fungal pulmonary infections after bone marrow transplantation: evaluation with radiography and CT. Radiology 1991; 178: 721-726.

47. Baron O, Guillaumé B, Moreau P, et al. Aggressive surgical management in localized pulmonary mycotic and nonmycotic infections for neutropenic patients with acute leukemia: report of eighteen cases. $J$ Thorac Cardiovasc Surg 1998; 115: 63-69.

48. Machetti M, Feasi M, Mordini N, et al. Comparison of an enzyme immunoassay and a latex agglutination system for the diagnosis of invasive aspergillosis in bone marrow transplant recipients. Bone Marrow Transplant 1998; 21: 917-921.

49. Verweij PE, Stynen D, Rijs AJMM, de Pauw BE, Hoogkamp-Korstanje JAA, Meis JFGM. Sandwich enzyme-linked immunosorbent assay compared with pastorex agglutination test for diagnosing invasive aspergillosis in immunocompromised patients. J Clin Microbiol 1995; 33: 1912-1917.

50. Swanink CMA, Meis JFGM, Rijs AJMM, Donelly JP, Verweij PE. Specificity of a Sandwich enzymelinked immunosorbent assay for detecting aspergillus galactomannan. J Clin Microbiol 1997; 35: 257-260.

51. Rogers TRM, Haynes KA, Barnes RA. Value of antigen detection in predicting invasive pulmonary aspergillosis. Lancet 1990; 336: 1210-1213.

52. Maertens J, Verhaegen $\mathrm{J}$, Demuynck $\mathrm{H}$, et al. Autopsy-controlled prospective evaluation of serial screening for circulating galactomannan by a sandwich enzyme-linked immunosorbent assay for hematological patients at risk for invasive aspergillosis. J Clin Microbiol 1999; 31: 3223-3228.

53. Bretagne S, Marmorat-Khuong A, Kuentz M, Latgé JP, Bart-Delabesse E, Cordonnier C. Serum aspergillus galactomannan antigen testing by sandwich ELISA: Practical use in neutropenic patients. $J$ Infect 1997; 35: 7-15.

54. Maertens J, Verhaegen J, Lagrou K, Van Eldere J, Boogaerts M. Screeening for circulating galactomannan as a noninvasive diagnostic tool for invasive aspergillosis in prolonged neutropenic patients and stem cell transplantation recipients: a prospective validation. Blood 2001; 97: 1604-1610.

55. Obayashi T, Yoshida M, Mori T, et al. Plasma (1->3)beta-D-glucan measurement in diagnosis of invasive deep mycosis and fungal febrile episodes. Lancet 1995; 345: 17-20.

56. Weig M, Frosch M, Tintelnot K, et al. Use of recombinant mitogillin for improved serodiagnosis of aspergillus fumigatus-associated diseases. J Clin Microbiol 2001; 39: 1721-1730.

57. Patterson TF, Miniter P, Patterson JE, Rappeport $\mathrm{JM}$, Andriole VT. Aspergillus antigen detection in the diagnosis of invasive aspergillosis. J Infect Dis 1995; 171: $1553-1558$

58. Yamakami Y, Hashimoto A, Tokimatsu I, Nasu M. PCR detection of DNA specific for aspergillus species in serum of patients with invasive aspergillosis. J Clin Microbiol 1996; 34: 2464-2468.

59. Bretagne S, Costa JM, Bart-Delabesse E, Dhédin N, Rieux C, Cordonnier C. Comparison of serum galactomannan antigen detection and competitive 
polymerase chain reaction for diagnosing invasive aspergillosis. Clin Infect Dis 1998; 26: 1407-1412.

60. Hebart H, Löffler J, Meisner C, et al. Early detection of aspergillus infection after allogeneic stem cell transplantation by polymerase chain reaction screening. $J$ Infect Dis 2000; 181: 1713-1719.

61. Becker MJ, De Marie S, Willemse D, Verbrugh HA, Bakker-Woudenberg IAJM. Quantitative galactomannan detection is superior to PCR in diagnosing and monitoring invasive pulmonary aspergillosis in an experimental rat model. J Clin Microbiol 2000; 38: 1434-1438.

62. Einsele H, Hebart H, Roller G, et al. Detection and identification of fungal pathogens in blood by using molecular probes. J Clin Microbiol 1997; 35: 1353-1360.

63. Skiladny $\mathrm{H}$, Buchheidt $\mathrm{D}$, Baust $\mathrm{C}$, et al. Specific detection of aspergillus species in blood and bronchoalveolar lavage samples of immunocompromised patients by two step PCR. J Clin Microbiol 1999; 37 : 3865-3871.

64. Spreadbury C, Holden D, Aufauvre-Brown A, Bainbridge B, Cohen J. Detection of Aspergillus fumigatus by polymerase chain reaction. J Clin Microbiol 1993; 21: 615-621.

65. Costa C, Vidud D, Olivi M, Bart-Delabesse E, Vidaud M, Bretagne S. Development of two real-time quantitative TaqMan PCR assays to detect circulating Aspergillus fumigatus DNA in serum. $J$ Microbiol Methods 2001; 44: 263-269.

66. Einsele H, Quabeck K, Muller KD, et al. Prediction of invasive pulmonary aspergillosis from colonisation of lower respiratory tract before marrow transplantation. Lancet 1998; 352: 1443.

67. Henry T, Iwen PC, Hinrichs SH. Identification of aspergillus species using internal transcribed spacer regions 1 and 2. J Clin Microbiol 2000; 38: 1510-1515.

68. Cordonnier C, Escudier E, Verra F, Brochard L, Bernaudin JF, Fleury-Feith J. Bronchoalveolar lavage during neutropenic episodes: diagnostic yield and cellular pattern. Eur Respir J 1994; 7: 114-120.

69. Huaringa AJ, Leyva FJ, Signes-Costa J, et al. Bronchoalveolar lavage in the diagnosis of pulmonary complication of bone marrow transplantation. Bone Marrow Transplant 2000; 25: 975-979.

70. Jantunen E, Piilonen A, Volin L, et al. Diagnostic aspects of invasive aspergillus infections in allogeneic BMT recipients. Bone Marrow Transplant 2000; 25: 867-871.

71. Horvath JA, Dummer S. The use of respiratory tract cultures in the diagnosis of invasive pulmonary aspergillosis. Am J Med 1996; 100: 171-178.

72. Reichenberger F, Habicht J, Matt P, et al. Diagnostic yield of bronchoscopy in histologically proven invasive pulmonary aspergillosis. Bone Marrow Transplant 1999; 24: 1195-1199.

73. Andrews CP, Weiner MH. Aspergillus antigen detection in bronchoalveolar lavage fluid from patients with invasive pulmonary aspergillosis and aspergillomas. Am J Med 1982; 73: 372-380.

74. Rath PM, Oeffelke R, Müller KD, Ansorg R. Non-value of aspergillus antigen detection in bronchoalveolar lavage fluids of patients undergoing bone marrow transplantation. Mycoses 1996; 39: 367-370.

75. Verweij PE, Latgé JP, Rijs AJMM, et al. Comparison of antigen detection and PCR assay using bronchoalveolar lavage fluid for diagnosing invasive pulmonary aspergillosis in patients receiving treatment for hematological malignancies. J Clin Microbiol 1995; 33: $3150-3153$.

76. Tang CM, Holden DW, Aufauvre-Brown A, Cohen J. The detection of aspergillus spp. by the polymerase chain reaction and its evaluation in bronchoalveolar lavage fluid. Am Rev Respir Dis 1993; 148: 1313-1317.

77. Bretagne S, Costa JM, Marmorat-Khuong A, et al. Detection of aspergillus species DNA in bronchoalveolar lavage samples by competitive PCR. J Clin Microbiol 1995; 33: 1164-1168.

78. Cazzadori A, Di Perri G, Todeschini G, et al. Transbronchial biopsy in the diagnosis of pulmonary infiltrates in immunocompromised patients. Chest 1995; 107: 101-106.

79. Habicht JM, Gratwohl A, Tamm M, Drewe J, Proske M, Stulz P. Diagnostic and therapeutic thoracic surgery in leukemia and severe aplastic anemia. J Thorac Cardiovasc Surg 1997; 113: 982-988.

80. Denning DW, Lee JY, Hostetler JS, et al. NIAID mycoses study group multicenter trial of oral intraconazole therapy for invasive aspergillosis. $\mathrm{Am} \mathrm{J} \mathrm{Med}$ 1994; 97: 135-144.

81. Maertens J, Raad I, Sable CA, et al. Multicenter, noncomparative study to evaluate safety and efficacy of caspofungin in adults with invasive aspergillosis refractory or intolerant to amphotericin B, AMB lipid formulation, or azoles. 40th interscience conference on antimicrobial agents and chemotherapy. Toronto, Canada 2000; A1103: 371.

82. Withing S, Chambers ST, Beard ME, et al. Invasive aspergillosis in severely neutropenic patients over 18 years: impact of intranasal amphotericin B and HEPA filtration. $J$ Hosp Infect 1998; 38: 11-18.

83. Walsh TJ, Finberg RW, Arndt C, et al. Liposomal amphotericin B for empirical therapy in patients with persistent fever and neutropenia. New Engl J Med 1999; 340: 764-771.

84. Eriksson U, Seifert B, Schaffner A. Comparison of effects of amphotericin B desoxycholate infused over 4 or 24 hours: randomised controlled trial. BMJ 2001; 322: $1-6$.

85. Denning DW. Therapeutic outcome in invasive aspergillosis. Clin Infect Dis 1996; 23: 608-615.

86. Lin SJ, Schranz J, Teutsch SM. Aspergillus case fatality rate: systematic review of the literature. Clin Infect Dis 2001; 32: 358-366.

87. Yamada H, Kohno S, Koga H, Maesaki S, Kaku M. Topical treatment of pulmonary aspergilloma by antifungals. Chest 1993; 103: 1421-1425.

88. Veltri A, Anselmetti GC, Bartoli G, et al. Percutaneous treatment with amphotericin $\mathrm{B}$ of mycotic lung lesions from invasive aspergillosis: result in 10 immunocompromised patients. Eur Radiol 2000; 10: 1939-1944.

89. Bennett MR, Weinbaum DL, Fiehler PD. Chronic necrotizing pulmonary aspergillosis treated by endobronchial amphotericin B. South Med J 1990; 83: 829832.

90. Winkler J, Steiniger L, Plath A, et al. Fiberoptic local endobronchial instillation of antimycotic agents (Amphotericin B or Miconazol) as an additive treatment of invasive aspergillosis and aspergilloma of the lung. Eur Respir J 1997; 10: S323.

91. Hughes WT, Armstrong D, Bodey GP, et al. 1997 Guidelines for the use of antimicrobial agents in neutropenic patients with unexplained fever. Clin Infect Dis 1997; 25: 551-573. 
92. EORTC international antimicrobial therapy cooperative group. Empiric antifungal therapy in febrile granulocytopenic patients. Am J Med 1989; 86: 668672.

93. Gotzsche PC, Johansen HK. Meta-analysis of prophylactic or empirical antifungal treatment versus placebo or no treatment in patients with cancer complicated by neutropenia. BMJ 1997; 314: 1238 1244.

94. Dubios J, Bartter T, Gryn J, Pratter MR. The physiological effects of inhaled amphotericin B. Chest 1995; 108: 750-753.

95. Schwartz S, Behre G, Heinemann V, et al. Aerolized amphotericin B inhalations as prophylaxis of invasive aspergillosis infections during prolonged neutropenia: result of a prospective randomized multicenter trial. Blood 1999; 93: 3654-3661.

96. Stevens DA, Kan VL, Judson MA, et al. Practice guidelines for diseases caused by aspergillus. Clin Infect Dis 2000; 30: 696-709.

97. Wong-Beringer A, Jacobs RA, Guglielmo BJ. Lipid formulations of amphotericin B: clinical efficacy and toxicities. Clin Infect Dis 1998; 27: 603-618.

98. Hay RJ. Liposomal amphotericin B, AmBisome. J Infect 1994; 28: 35-43.

99. Ellis M, Spence D, de Pauw B, et al. An EORTC international multicenter randomized trial comparing two dosages of liposomal amphotericin B for treatment of invasive aspergillosis. Clin Infect Dis 1998; 27: 1406-1412.

100. Kelsey SM, Goldman JM, McCann S, et al. Liposomal amphotericin (AmBisome) in the prophylaxis of fungal infections in neutropenic patients: a randomised, double-blind, placebo-controlled study. Bone Marrow Transplant 1999; 23: 163-168.

101. White MH, Anaissie EJ, Kusne S, et al. Amphotericin B colloidal dispersion vs. amphotericin B as therapy for invasive aspergillosis. Clin Infect Dis 1997; 24: 635642.

102. White MH, Bowden RA, Sandler ES, et al. Randomized, double-blind clinical trial of amphotericin B colloidal dispersion $v s$. amphotericin $\mathrm{B}$ in the empirical treatment of fever and neutropenia. Clin Infect Dis 1998; 27: 296-302.

103. Stevens DA. Overview of amphotericin B colloidal dispersion (Amphocil). J Infect 1994; 28: 45-49.

104. Timmers GJ, Zweegman S, Simoons-Smit AM, van Loenen AC, Touw D, Huijgens PC. Amphotericin B colloidal dispersion (Amphocil) vs fluconazole for the prevention of fungal infections in neutropenic patients: data of a prematurely stopped clinical trial. Bone Marrow Transplant 2000; 25: 879-884.

105. Walsh TJ, Hiemenz JW, Seibel NL, et al. Amphotericin B lipid complex for invasive fungal infections: analysis of safety and efficacy in 556 cases. Clin Infect Dis 1998; 26: 1383-1396.

106. Wingard JR, White MH, Anaissie E, Raffalli J, Goodman J, Arrieta A. A randomized, double-blind comparative trial evaluation the safety of liposomal amphotericin B versus amphotericin B lipid complex in the empirical treatment of febrile neutropenia. Clin Infect Dis 2000; 31: 1155-1163.

107. Schöffski P, Freund M, Wunder R, et al. Safety and toxicity of amphotericin B in glucose $5 \%$ or intralipid $20 \%$ in neutropenic patients with pneumonia or fever of unknown origin: randomised study. BMJ 1998; 317 : 379-384.
108. Moore CB, Sayers N, Mosquera J, Slaven J, Denning DW. Antifungal drug resistance in aspergillus. J Infect 2000; 41: 203-220.

109. Neely MN, Ghannoum MA. The exciting future of antifungal therapy. Eur J Clin Microbiol Infect Dis 2000; 19: 897-914.

110. Georgiev VS. Treatment and developmental therapeutics in aspergillosis. Respiration 1992; 59: 303-313.

111. Prentice HG, Caillot D, Dupont B, Menichetti F, Schuler U. Oral and intravenous itraconazole for systemic fungal infections in neutropenic haematological patients: meeting report. Acta Haematol 1999; 101: 56-62.

112. Stevens DA, Lee JY. Analysis of compassionate use intraconazole therapy for invasive aspergillosis by the NIAID mycoses study group criteria. Arch Intern Med 1997; 157: 1857-1862.

113. Kibbler CC. Antifungal prophylaxis with itraconazole oral solution in neutropenic patients. Mycoses 1999; 42: 121-124.

114. Glasmacher A, Hahn C, Leutner C, et al. Breakthrough invasive fungal infections in neutropenic patients after prophylaxis with itraconazole. Mycoses 1999; 42: 443-451.

115. Harousseau JL, Dekker AW, Stamatoullas-Bastard A, et al. Itraconazole oral solution for primary prophylaxis of fungal infections in patients with hematological malignancy and profound neutropenia: a randomized double-blind, double-placebo, multicenter trial comparing itraconazole and amphotericin B. Antimicrobial Agents Chemother 2000; 44: 1887-1893.

116. Denning DW, Venkateswarlu K, Oakley $\mathrm{Kl}$, et al. Itraconazole resistance in aspergillus fumigatus. Antimicrob Agents Chemother 1997; 41: 1364-1368.

117. Dannaoui E, Borel E, Monier MF, Piens MA, Picot S, Persat F. Acquired itraconazole resistance in Aspergillus fumigatus. J Antimicrob Chemother 2001; 47: 333-340.

118. Chandrasekar PH, Cutright J, Manavathu E. Efficacy of voriconazole against invasive pulmonary aspergillosis in a guinea-pig model. J Antimicrob Chemother 2000; 45: 673-676.

119. Murphy M, Bernard EM, Ishimaru T, Armstrong D. Activity of voriconazole (UK-109,496) against clinical isolates of aspergillus species and its effectiveness in an experimental model of invasive pulmonary aspergillosis. Anitmicrob Agents Chemother 1997; 41: 696-698.

120. Walsh TJ, Pappas P, Winston DJ, et al. Voriconazole compared with liposomal amphotericin B for empirical antifungal therapy in patients with neutropenia and persistent fever. N Engl J Med 2002; 346: 225-234.

121. Espinel-Ingroff A. Comparison of in vitro activities of the new triazole SCH56592 and the echinocandines MK-0991 (L-743,872) and LY303366 against opportunistic filamentous and dimorphic fungi and yeasts. J Clin Microbiol 1998; 36: 2950-2956.

122. Roberts J, Schock K, Marino S, Andriole VT. Efficacy of two new antifungal agents, the triazole ravuconazole and the echinocandin LY-303366 in an experimental model of invasive aspergillosis. Antimicrob Agents Chemother 2000; 44: 3381-3388.

123. Onishi J, Meinz M, Thompson J, et al. Discovery of novel antifungal $(1,3)-\beta$-D-glucan synthesis inhibitors. Antimicrob Agents Chemother 2000; 44: 368-377.

124. Denning DW. Echinocandins and pneumocandins - a new antifungal class with a novel mode of action. J Antimicrob Chemother 1997; 40: 611-614. 
125. Petraitis V, Petraitiene R, Groll AH, et al. Antifungal efficacy, safety, and single-dose pharmacokinetics of LY303366, a novel echinocandin B, in experimental pulmonary aspergillosis in persistently neutropenic rabbits. Antimicrob Agents Chemother 1998; 42: 2898-2905.

126. Oakley KL, Moore CB, Denning DW. Comparison of in vitro activity of liposomal nystatin against aspergillus species with those of nystatin, amphotericin B (AB) deoxycholate, AB colloidal dispersion, liposmal AB, AB lipid complex, and itraconazole. Antimicrob Agents Chemother 1999; 43: 1264-1266.

127. Georgopapadakou NH, Walsh TJ. Antifungal agents: chemotherapy target and immunologic strategies. Antimicrob Agent Chemother 1999; 401: 279-291.

128. Popp AI, White MH, Quadri T, Walshe L, Armstrong D. Amphotericin B with and without itraconazole for invasive aspergillosis: A three-year retrospective study. Int J Infect Dis 1999; 3: 157-160.

129. Schaffner A, Bohler A. Amphotericin B refractory aspergillosis after itraconazole: evidence for significant antagonism. Mycoses 1993; 36: 421-424.

130. Verweij PE, Donnelly JP, Kullberg BJ, Meis JFGM, De Pauw BE. Amphotericin B versus Amphotericin B plus 5-Flucytosine: Poor Results in the Treatment of Proven Systemic Mycoses in Neutropenic Patients. Infection 1994; 22: 81-85.

131. Nemunaitis J, Shannon-Dorcy K, Appelbaum FR, et al. Long-term follow-up of patients with invasive fungal disease who received adjunctive therapy with recombinant human macrophage colony-stimulating factor. Blood 1993; 82: 1422-1427.

132. Gorelik O, Cohen N, Shpirer I, et al. Fatal haemoptysis induced by invasive pulmonary aspergillosis in patients with acute leukemia during bone marrow and clinical remission: report of two cases and review of the literature. J Infect 2000; 41: 277-282.

133. Todeschini G, Murari C, Bonesi R, et al. Invasive aspergillosis in neuropenic patients: rapid neutrophil recovery is a risk factor for severe pulmonary complications. Eur J Clin Invest 1999; 29: 453-457.
134. Bhatia S, McCullough J, Perry EH, Clay M, Ramsay NK, Neglia JP. Granulocyte transfusions: efficacy in treating fungal infections in neutropenic patients following bone marrow transplantation. Transfusion 1994; 34: 226-232.

135. Dignani MC, Anaissie EJ, Hester JP, et al. Treatment of neutropenia-related fungal infections with granulocyte colony-stimulating factor-elicited white blood cell transfusions: a pilot study. Leukemia 1997; 11: 16211630.

136. Young VK, Maghur HA, Luke DA, McGovern EM. Operation for cavitating invasive pulmonary aspergillosis in immunocompromised patients. Ann Thorac Surg 1992; 53: 621-624.

137. Salerno CT, Ouyang DW, Pederson TS, et al. Surgical therapy for pulmonary aspergillosis in immunocompromised patients. Ann Thorac Surg 1998; 65: 1415-1419.

138. Habicht JM, Passweg J, Kuhne T, Leibundgut K, Zerkowski HR. Successful local excision and longterm survival for invasive pulmonary aspergillosis during neutropenia after bone marrow transplantation. J Thorac Cardiovasc Surg 2000; 119: 12861287.

139. Habicht JM, Reichenberger F, Gratwohl A, Zerkowski HR, Tamm M. Surgical aspects of resection for suspected invasive pulmonary fungal infection in neutropenic patients. Ann Thorac Surg 1999; 68: $321-325$.

140. Pidhorecki I, Urschel J, Anderson T. Resection of invasive pulmonary aspergillosis in immunocompromised patients. Ann Surg Oncol 2000; 7: 312-317.

141. Habicht JM, Matt P, Passweg JR, et al. Invasive pulmonary fungal infection in hematological patients: is resection effective? The Hematology J 2001; 2: 250 256.

142. Ribrag V, Dreyfus F, Venot A, Leblong V, Lanore JJ, Varet B. Prognostic factors of invasive pulmonary aspergillosis in leukemic patients. Leuk Lymphoma 1993; 10: 317-321. 